\title{
Integrating Physical Card Games with Digital Video Games through RFID Tagging
}

\author{
Jude Joseph L. Martinez and Kevin Tjahjadi
}

\begin{abstract}
Collectible card games can be 'addictive', more so if the game allows the player to duel against another player using the collectible cards. More often than not, a collectible card game has its digital video game counterpart. Currently physical card games and digital games do not interact with one another. The authors believe that the user experience could be significantly improved by allowing the physical cards to interact with the digital video game. The technology being used by the authors in the development of this paper is RFID Technology. RFID (Radio Frequency Identification) is a technology that relies on radio frequency to communicate with data storing tags. The basic concept of this paper is tagging cards with RFID tags to make it detectable by the computer via RFID Readers. The aim of this paper is to combine physical card games with digital video games. This paper also strives to achieve a better user experience for the gamer by using this technology.
\end{abstract}

Index Terms-Collectible card game, digital video game, multiple RFID readers, new technology

\section{INTRODUCTION}

In order for computers to recognize analogous objects, identification systems are needed. Automatic Identification and Data Capture (AIDC) is one of the methods of automatically identifying objects and inputting the data of that object into computers.

Objects can be tagged with barcodes, Quick Response (QR) code, or even the latest technology using Radio Frequency Identification (RFID). In turn, specific input devices such as scanners or cameras are needed to obtain that identification data. Barcodes, patented in 1952 [1], have been used as a mean of identifying products being sold in stores since then. There has been development of other AIDC systems in the market, but the low cost of barcodes prevented other systems from entering the market until the introduction of RFID over 40 years later.

RFID is an AIDC system comprised of one or more readers and one or more Radio Frequency Tags (RFT) which communicate over electromagnetic radiation spectrums wirelessly (http://www.aimglobal.org/technologies/rfid/rfid_Glossary.a sp). Early research into RFID was conducted by R.F. Harrington in his paper "Theory of Loaded Scatterers" in 1964. That decade saw a boom in RFID-related inventions [1]. Since the RFID has enjoyed hundreds, if not thousands, of applications ranging from theft prevention, authorization

Manuscript revised March 20, 2013; revised May 8, 2013.

The authors are with the School of Computer Science, Bina Nusantara University Jakarta, Indonesia (e-mail: jmartinez@binus.edu; kevintjahjadi@gmail.com). systems, library systems, and as a means of conducting transactions in the form of a financial smart card. Examples of these cards include but are not limited to the 'Flazz' card (vendor: BCA bank) and the 'E-Toll Card' (vendor: Mandiri bank). The authors have also developed another use of RFID for digital entertainment purposes. The entertainment would take the form of a computer-augmented card game in which people compete. Currently, video games in which people play traditional card games on a console do not have a physical component that represents a game character. Therefore, the author would like to create a card-playing video game that has tangible object representation. These will be RFID collectible games where players can compete against another player using their RFID tagged cards. The authors aim to combine a traditional, physical card game with a digital video game.

RFID is an AIDC system comprised of one or more readers and one or more Radio Frequency Tags (RFT) which communicate over electromagnetic radiation spectrums wirelessly (http://www.aimglobal.org/technologies/rfid/rfid_Glossary.a sp). Early research into RFID was conducted by R.F. Harrington in his paper "Theory of Loaded Scatterers" in 1964. That decade saw a boom in RFID-related inventions [1]. Since the RFID has enjoyed hundreds, if not thousands, of applications ranging from theft prevention, authorization systems, library systems, and as a means of conducting transactions in the form of a financial smart card. Examples of these cards include but are not limited to the 'Flazz' card (vendor: BCA bank) and the 'E-Toll Card' (vendor: Mandiri bank). The authors have also developed another use of RFID for digital entertainment purposes. The entertainment would take the form of a computer-augmented card game in which people compete. Currently, video games in which people play traditional card games on a console do not have a physical component that represents a game character. Therefore, the author would like to create a card-playing video game that has tangible object representation. These will be RFID collectible games where players can compete against another player using their RFID tagged cards. The authors aim to combine a traditional, physical card game with a digital video game.

This research will be aimed at designing and developing an application prototype that would open up new possibilities in the use of RFID for entertainment use. This paper will focus on the application of RFID technology in the gaming industry and in the use of RFID tags as playable objects. The system resulting from this paper is hoped to revolutionize the gaming industry and will open up new possibilities of RFID usages for entertainment purposes. In the future however, this research may also prove useful in the development of pervasive computers. 


\section{PROBLEM ANALYSIS}

\section{A. Choosing the Type of Tagging Technology}

Many technologies can be used to apply AIDC; the following section analyzes such technologies and compares them to RFID technology. AIDC technology can be categorized as either 'contact' or 'contactless'. This paper discusses RFID technology, which is a contactless identification technology; therefore, contact identification technology will not be included in this paper. In choosing the type of AIDC technology, the following criteria must be met:

- The technology must be readily available (ubiquity) - if it is difficult to obtain it is not useful.

- The technology must be dedicated to a programming environment - to hasten development use.

- The technology must be flexible - to promote scalability which also promotes future work.

- The technology must be able to store a lot of data - a large amount of data will be transferred using the technology

- The technology must be financially available expensive hardware will make the technology less accessible.

- The technology must support the game, not limit or hinder the game - technologies that limit/hinder the movement of the players will reduce the gaming experience, and above all it must not restrain the players.

\section{1) Barcode}

Barcode could be described as an 'optical Morse code'. The dots and dashes in the Morse code are the acoustic equivalent of the black bars and white spaces which are used to convey machine-readable data to the computer. Barcode labels are read with a scanner that convert's the label's data into numbers and/or letters to the computer. (http://www.dataid.com/whatisbarcode.htm)

Barcodes are extremely financially viable, durable and robust. They are easily machine readable and can transmit the alphanumerical code to the program directly without the need for specific protocol or extra programming. They are not very convenient in gaming, however. The tags can only be read in the line of sight of the readers, meaning when a player's hands cover the cards/labels during the game which will happen a lot during the course of an average game - the labels will be unreadable.

\section{2) Near field communication (NFC)}

Near Field Communication (NFC) is not much different from RFID in theory. NFC-enabled devices can communicate over an electromagnetic field wirelessly (http://www.mobileburn.com/definition.jsp?term=NFC).

The technology has been developed mainly in conjunction with the rise of the mobile phone. It also possesses more versatility than

RFID (http://www.nearfieldcommunication.org/qr-codes.html).

NFC is better than RFID in terms of data management. NFC tags can be modified by the device attached to it, in order to customize the data that is being communicated. The drawback is that NFC tags are paired with their respective digital devices which modify the data, i.e. mobile devices, making them not very convenient as a playing material.

\section{3) Bluetooth}

Bluetooth, another wireless communication method, is a technology which was first invented by Ericsson in 1994. It transfers data over radio waves, through the $2.4-2.485 \mathrm{GHz}$ transmission

band.

(http://www.techradar.com/news/phoneand-

communications/mobile-phones/what-is-bluetooth-1063913) Bluetooth is good as a means of transferring information between devices. However, it is not a very effective as a tagging mechanism because the Bluetooth needs to be active in the devices, in contrast to the previously mentioned tagging mechanisms. It also has the same drawback as the NFC technology. The technology is paired to the device, making the tags big and not very convenient as a playing material.

\section{B. Comparing Wireless/Contactless Technologies}

This study was compelled to use wireless/contactless technologies. Magnetic stripes and contact smart cards were not included as they hinder the gaming experience. Applying the criteria mentioned earlier in the study, RFID satisfied most of the categories. Barcodes are very goods in term of accessibility and price range, with it being commonly used everywhere in our lives. However, it is lacking in compatibility to be used in the game. When the tags are covered or broken, the tags will be unreadable.

NFC technologies are very good compared to RFID technologies when they are compared as is. However, since the tags will be used for gaming purposes, NFC technologies have drawbacks compared to RFID technologies. NFC tags are comparably more expensive and need to be paired with a digital device, making it big and inconvenient to be used as a playing object.

Bluetooth technologies are not much different from NFC technologies, paired with their devices and the technology is inconvenient to use in this kind of gaming.

RFID technology proves very compatible for use in this kind of gaming experience. Tags are readily available; they have been used in many companies across the author's homeland, Indonesia, to replace barcode technologies. The tags are also very affordable, even though the reader is not very cheap on its own. The tags are small and can be easily hidden from the user. Development of RFID is very flexible; NFC technologies can read RFID tags as the two depend on the same underlying concept. APIs are available as unofficial releases by other users. The API however is enough for this kind of environment.

\section{System Design}

RFID has a lot of capabilities and, conversely, limitations in its usage depending on the hardware being used. The design the authors employed is based on the limitations posed by the hardware that was available for use in this prototype. The basic concept combines physical card games and digital video games so that users may play digital video game using physical cards. A significant example of the benefit this paper could provide is the interactivity of card game tournaments. For example, currently card game tournaments are held only on tables where spectators need to 
gather around the table to have a look at the match. By implementing the product of this paper, the tournament could be held at the stage with a screen at the background which shows the progression of the game interactively. This not only improves the user experience of the players but also the spectators.

\begin{tabular}{|c|c|c|c|c|}
\hline & Barcode & NFC & Bluetooth & RFID \\
\hline Ubiquity & Yes & $\begin{array}{l}\text { Not yet in } \\
\text { Indonesia }\end{array}$ & Yes & Yes \\
\hline $\begin{array}{c}\text { Dedicated } \\
\text { API }\end{array}$ & No need & $\begin{array}{l}\text { No } \\
\text { information }\end{array}$ & $\begin{array}{l}\text { No } \\
\text { information }\end{array}$ & Yes \\
\hline Flexibility & $\begin{array}{l}\text { Very } \\
\text { High }\end{array}$ & High & Low & $\begin{array}{l}\text { Very High } \\
\text { (NFC } \\
\text { Compatible) }\end{array}$ \\
\hline Capacity & $\begin{array}{l}8 \text { bits to } \\
21 * 21 \\
\text { bits }\end{array}$ & $\begin{array}{l}\text { Depends on } \\
\text { device }\end{array}$ & None & $\begin{array}{l}64 \text { bits to } 4 \\
\text { Kbytes }\end{array}$ \\
\hline Price & $\begin{array}{l}\text { Price of } \\
\text { paper } \\
\text { Rp } 100\end{array}$ & $\begin{array}{l}\text { Tags }=\text { Rp } \\
5,000 \\
\text { Reader }=\text { Rp } \\
1,000,000\end{array}$ & $\operatorname{Rp} 20,000$ & $\begin{array}{l}\text { Tags = Rp } \\
700 \\
\text { Reader }= \\
\text { Rp 25,000 - } \\
150,000\end{array}$ \\
\hline $\begin{array}{c}\text { Ease of } \\
\text { use }\end{array}$ & $\begin{array}{l}\text { Tags } \\
\text { need to } \\
\text { be in } \\
\text { line of } \\
\text { sight. } \\
\text { Restrain } \\
\text { user not } \\
\text { to block } \\
\text { it }\end{array}$ & $\begin{array}{l}\text { Tags are } \\
\text { paired with } \\
\text { devices, } \\
\text { inconvenient } \\
\text { to play with } \\
\text { big objects }\end{array}$ & $\begin{array}{l}\text { Tags are } \\
\text { paired with } \\
\text { devices, } \\
\text { inconvenient } \\
\text { to play with } \\
\text { big objects }\end{array}$ & $\begin{array}{l}\text { Tags are } \\
\text { small, } \\
\text { making it } \\
\text { very } \\
\text { convenient } \\
\text { to hide from } \\
\text { user } \\
\text { knowledge }\end{array}$ \\
\hline
\end{tabular}

\section{A. Game Concept}

The author's aim is to blend a physical card game with a digital video game with details of the idea of the game shown below.

\section{1) Game phase}

The game is separated into 3 phases: the Draw Phase, the Main Phase, and the End Phase. The game progresses with the first player starting in the Draw Phase, moving through to the Main Phase, and finally the End Phase and then the next player's Draw Phase starts. The game ends when any of the players has equal to or less than 0 health during the other player's End Turn.

2) Card type

There are 4 (four) card types involved in the game. These are: Creature, Spell, Character and Energy Source.

\section{3) Elements}

The game revolves around elements as its core. Creatures, spells, and energy sources have elements attributed to them. To summon a creature or cast a spell, the player needs to provide sufficient energies of the specified elements as predefined in the cards. The elements do not provide any advantage over one another. It only serves as an assignment towards effect. Example: fire is attributed to offense so the spells based on fire is offensive spell and so on and so forth. There are 4 (four) elements being implemented in the prototype and they are as follows: Fire, Water, Earth and Air.

\section{4) Game Field}

Fig. 1 shows that the gaming field uses only two card readers, one at each end of the screen/monitor

Fig. 2 show what the game will look like in the monitor. The energy sources placed nearest to the player followed with the energy pool and the farthest from the player is their creatures. The energy pool is the energy usable to summon creature or cast spell. The energy source is the one that produces energy at the draw phase, filling up the energy pool.

\section{5) Rule set}

Following is the set of rules implemented in the game:

- Each player starts with 100 health points

- The first player to lose all of his health loses

- The minimum number of cards in the deck is 25

- The maximum number of cards in the deck is 35

- To play the card, the player must fulfill the required amount of energy of the specific element as predefined in the cards

- The used cards go to 'the grave' directly. This applies to Energy Sources and Spell Cards.

- The maximum number of creatures that a player can summon is 3

Winning condition is having the opposing player's health equivalent to or below 0 during the player's End Phase. Losing condition is to have the opposing player reduce their health to 0 or below by his End Phase.

\section{6) System data}

There will be 2 types of data utilised in this system. The first one is the card information which is stored in the RFID tags. The second is the $3 \mathrm{D}$ model of the cards. The information stored in the card is customizable by the author. It follows the following encoding technique devised by the authors, using Fig. 3 and 4 as a reference point for encoding.

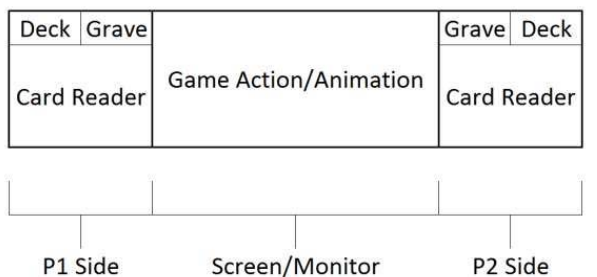

Fig. 1. Gamefield

\begin{tabular}{|c|c|c|c|c|c|}
\hline $\begin{array}{c}\text { Energy } \\
\text { Source } 1\end{array}$ & $\begin{array}{l}\text { Energy } \\
\text { Pool } 1\end{array}$ & $\begin{array}{l}\text { Player's } \\
\text { Avatar }\end{array}$ & $\begin{array}{l}\text { Player's } \\
\text { Avatar }\end{array}$ & $\begin{array}{l}\text { Energy } \\
\text { Pool } 1\end{array}$ & $\begin{array}{c}\text { Energy } \\
\text { Source } 1\end{array}$ \\
\hline $\begin{array}{c}\text { Energy } \\
\text { Source } 2\end{array}$ & $\begin{array}{l}\text { Energy } \\
\text { Pool } 2\end{array}$ & Creature 1 & Creature 1 & $\begin{array}{l}\text { Energy } \\
\text { Pool } 2\end{array}$ & $\begin{array}{c}\text { Energy } \\
\text { Source } 2\end{array}$ \\
\hline $\begin{array}{c}\text { Energy } \\
\text { Source } 3\end{array}$ & $\begin{array}{l}\text { Energy } \\
\text { Pool } 3\end{array}$ & Creature 2 & Creature 2 & $\begin{array}{l}\text { Energy } \\
\text { Pool } 3\end{array}$ & $\begin{array}{c}\text { Energy } \\
\text { Source } 3\end{array}$ \\
\hline $\begin{array}{c}\text { Energy } \\
\text { Source } 4\end{array}$ & $\begin{array}{l}\text { Energy } \\
\text { Pool } 4\end{array}$ & Creature 3 & Creature 3 & $\begin{array}{l}\text { Energy } \\
\text { Pool } 4\end{array}$ & $\begin{array}{c}\text { Energy } \\
\text { Source } 4\end{array}$ \\
\hline
\end{tabular}

Fig. 2. Screen information division

\begin{tabular}{|l|c|l|l|c|}
\hline Sector 0 & $\begin{array}{c}\text { Block 0 } \\
\text { Manufacturer Block }\end{array}$ & Block 1 & Block 2 & $\begin{array}{c}\text { Block 3 } \\
\text { Sector Trailer }\end{array}$ \\
\hline Sector 1 & Block 4 & Block 5 & Block 6 & $\begin{array}{c}\text { Block 7 } \\
\text { Sector Trailer }\end{array}$ \\
\hline Sector 2 & Block 8 & Block 9 & Block 10 & $\begin{array}{c}\text { Block 11 } \\
\text { Sector Trailer }\end{array}$ \\
\hline Sector ... & Block ... & Block ... & Block ... & $\begin{array}{c}\text { Block ... } \\
\text { Sector Trailer }\end{array}$ \\
\hline Sector 15 & Block 60 & Block 61 & Block 62 & $\begin{array}{c}\text { Block 63 } \\
\text { Sector Trailer }\end{array}$ \\
\hline
\end{tabular}

Fig. 3. hMifare 1K block layout

The above figure is the block layout for Mifare 1K RFID card. There are 16 sectors in total, with 4 blocks in each sector. The last block in each sector is the 'sector trailer' which holds the key to authenticate communication with the card as well as the permission control. Those last blocks in each sector cannot be used to store data. The very first block is the manufacturer block which is write-protected making it 
also unusable to store data. The total effective storage is $3 \times 15+2$ blocks $=47$ blocks. Each block can store 16 bytes of information. Therefore the total bytes of effective data are 752 bytes.

\begin{tabular}{|c|c|c|c|c|c|c|c|c|c|c|c|c|c|c|c|}
\hline \multicolumn{2}{|c|}{0} & \multicolumn{2}{|c|}{1} & \multicolumn{2}{c|}{2} & \multicolumn{2}{c|}{3} & \multicolumn{2}{c|}{4} & \multicolumn{2}{|c|}{5} & \multicolumn{2}{|c|}{6} & \multicolumn{2}{|c|}{7} \\
\hline $\mathrm{a}$ & $\mathrm{b}$ & $\mathrm{a}$ & $\mathrm{b}$ & $\mathrm{a}$ & $\mathrm{b}$ & $\mathrm{a}$ & $\mathrm{b}$ & $\mathrm{a}$ & $\mathrm{b}$ & $\mathrm{a}$ & $\mathrm{b}$ & $\mathrm{a}$ & $\mathrm{b}$ & $\mathrm{a}$ & $\mathrm{b}$ \\
\hline $\mathrm{8}$ & \multicolumn{2}{|c|}{9} & \multicolumn{1}{|c|}{10} & \multicolumn{1}{|c|}{11} & \multicolumn{1}{|c|}{12} & \multicolumn{1}{|c|}{13} & \multicolumn{1}{|c|}{14} & \multicolumn{1}{c|}{15} \\
\hline $\mathrm{a}$ & $\mathrm{b}$ & $\mathrm{a}$ & $\mathrm{b}$ & $\mathrm{a}$ & $\mathrm{b}$ & $\mathrm{a}$ & $\mathrm{b}$ & $\mathrm{a}$ & $\mathrm{b}$ & $\mathrm{a}$ & $\mathrm{b}$ & $\mathrm{a}$ & $\mathrm{b}$ & $\mathrm{a}$ & $\mathrm{b}$ \\
\hline
\end{tabular}

Fig. 4. Half bye layout block

The figure above is used as a reference to explain the following card encoding.

\section{7) Gameplay}

Players will first undergo the Character Recognition Phase. Both players must place their Character cards in the two readers. Then the Draw Phase ensues. The first draw phase will do nothing since there is no energy to produce. Generally, however, the drawing phase will produce energy for the player based on their energy sources. After the player has finished checking the condition of the Draw Phase, players can continue by ending the Draw Phase by clicking on the Draw button at the top of the gaming screen. The next phase is the Main Phase where the players can play their cards. In the Main Phase, players can click on the Main button at the top of the gaming screen. Lastly, players will be brought to the End Phase, where the damage will be calculated against the other player, and buffs (temporary changes in status) reverted to normal. During the End Phase, if the opposing player has not lost all of his health, the turn shifts to the opposing player's Draw Phase.

\section{RESEARCH FINDING AND ANALYSIS}

The authors built a prototype to combine a physical game and a digital video game through the means of RFID tagged cards. The prototype is built upon the Omnikey CardMan 5321 system as the RFID card reader and Mifare $1 \mathrm{~K}$ as the RFID cards. The capabilities and limitations of the hardware will be explained below. The authors also provide alternative solutions to overcome these limitations.

\section{A. Capabilities of the Omnikey Cardman 5321}

The following are some of the capabilities of the Omnikey CardMan [2]:

- Read and write capabilities

Read command reads the data block from the tags' card data. Write or Update command writes the data block to the tag's card data. To read or write, login needs to be executed to the sector in which the data is located.

- Built in anti-collision

Omnikey CardMan 5321 has built in anti-collision mechanism ensuring only a single card is read at a time. This eliminates errors caused by interference produced in case there are two or more cards which respond to the reader's frequency. This capability however is also a limitation for this prototype.

- Secure Communication

There are 7 security measures being implemented by Omnikey CardMan 5321. Such measures are:

Application host and reader authentication
Authentication between the host application and reader must be completed before a session can be initiated.

Data transfer confidentiality

The Omnikey CardMan 5321 has a built-in system that protects against eavesdropping and replays attacks on USB traffic.

Data transfer integrity

The Omnikey CardMan 5321 ensures that transmitted data is correct as it is meant to be.

Reader and card authentication

Authentication between the reader and the card must be done manually before the card is allowed to be read and/or written. The authentication is done using shared secret application keys. There are two keys which can be modified and be given different rights.

For example, key A can read and write whilst key B can only read.

Radio frequency transmission confidentiality

The Omnikey CardMan 5321 will cancel card access in the presence of another reader nearby. This is done to eliminate the possibility of the other reader getting the information being communicated.

Radio frequency transmission integrity

The reader ensures that communicated information will be valid whether it is read or written.

Data transmission protection

The Omnikey CardMan 5321 has built-in data protection against data transmission from other programs that is trying to copy or edit the data.

\section{B. Limitations of the Omnikey CardMan 5321}

The Omnikey CardMan 5321 proves enough for simple gaming purposes. However, there are limitations posed by the hardware that limits the gaming experience. It is not fatal but had there been no limitations it would have improved the gaming experiences greatly. Such limitations are:

- Built in anti-collision

Whilst it is a capability, it is also a limitation. This means that the reader is unable to read more than one card at a time. The built in anti-collision prevents the reader from building a new connection to another RFID tag if there is still a card communicating with the reader. According to information from the customer support representative of the Omnikey CardMan 5321 it is unable to read multiple tags because of the manufacturer's driver that has an anti-collision algorithm.

- Reading range

The Omnikey CardMan 5321 uses $13.56 \mathrm{MHz}$ transmission [22] to communicate with the card. With the 13.56 MHz frequency, theoretically, the reader should be able to read tags up to 3.5 meters distance away [3]. However, on trial with the prototype, the reader was only capable of accessing the card from around 3 centimeters away. This will almost certainly hinder the user experience of the application.

\section{Suggestions on Alternative Readers}

Taking into consideration the limitations posed by the Omnikey CardMan 5321, the authors investigated another RFID reader with more advanced capabilities compared with the Omnikey CardMan 5321. The investigated hardware was Texas Instrument's TRF 7960. 
Texas Instrument's TRF 7960 reader is capable of an interrupt handler routine, anti-collision sequencing, multiple tag reading, among other abilities. [4]. The 'interrupt handler routine' handles conditions such as transmission complete, collision occurred, no response, etc.

Anti-collision processes the card so that the information received does not get mixed up. Multiple tag reading is used to read multiple tags one by one while maintaining communications to all of the tags. This reader proves beneficial in terms of eliminating limitations produced by the Omnikey CardMan 5321. It is able to read multiple tags at once which may enhance the user experience.

\section{CONCLUSION AND RECOMMENDATION}

\section{A. Conclusion}

Collectible card games are very addictive, and digital video games are also very addictive. However, the two of them, even though they may have the same brand, may not relate to one another. There is no interface that could connect the physical card game with the digital video game.

RFID technology is a technology that utilizes radio frequency to communicate with RFID tagged items. It may obtain the ID of the card as well as the information stored in that card. By using this technology the authors created a prototype to enable blending of the physical card game with the digital video game.

The prototype is a simple card game where the user aims to beat the opposing user by reducing their 'health' to zero. Users can do this by summoning a creature and/or casting a spell. The prototype however was constrained by the hardware that the authors used. During the development stage, the authors found out that the Omnikey CardMan 5321 had certain limitations such as: the inability to read multiple cards at once and the short antenna coverage. These limitations, along with the fact that the number of readers the authors can get is limited, forced them to modify some of their original plans on the gaming experience and because of the limited number of readers, the authors modified the prototype to be able to work with a single reader for each player.

\section{B. Recommendation}

Myriad improvements can be done to the application. Such improvements cover but are not limited to the following:
- Using a more advanced reader to open up more possibilities for user experiences. Improvements may allow using one reader to process a lot of cards at the same time.

- Improving the application to be more scalable administrators should be able to add effects easily without changing codes.

- Improve animation -the authors were unable to create extravagant animation which may cause the prototype to lack a visual point of interest.

\section{REFERENCES}

[1] J. Landt, "The history of RFID," IEEE Potentials, vol. 24, no. 4, pp. 8-11,Oct.-Nov. 2005.

[2] Omnikey, CardMan 5x21-CL Reader Developer's Guide, Germany: OMNIKEY GmbH, 2007.

[3] F. Thornton et al, RFID Security, Rockland: Syngress Publishing, Inc., 2006.

[4] Texas Instrument, The TI-RFID TRF796x HF Reader IC.

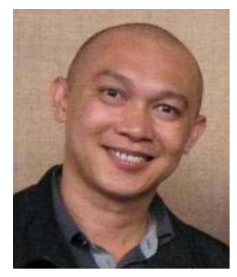

Jude J. L. Martinez completed his Masters in Computer Science at De La Salle University, Manila. Having finished a Bachelor's degree in Computer Science, he worked as an IT specialist and programmer for Philex Mining Corporation in Pasig City, Manila, Philippines. After getting ample experience in the field, he moved to the education sector and has since worked in academia while retaining a position as an IT consultant on one of the projects at Cypress Semiconductor Inc. He is adept at programming (C, Objective C, JAVA (J2SE/J2ME/JEE) and IA32 Assembly Language), troubleshooting hardware and tweaking software as a hobby. In addition, he is also inclined toward curriculum development and managing administrative tasks within the education sector. He is also a member of the Regional Quality Assessment Team (RQAT) CAR for Higher Education in the Cordillera Administrative Region, Philippines, the JAVA Education Development Initiative (JEDI) Community, Philippine Society of IT Educators (PSITE) and Association of Computing Machinery (ACM). His research interests include (but is not limited to) the fields of Software Engineering, Gaming Technology, Human Computer Interaction (HCI), Pervasive and Mobile Computing.

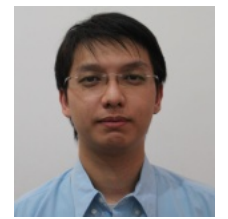

Kevin Tjahjadi is currently working at PT. User Inspired as a web developer. He graduated from BINUS INTERNATIONAL where he participated in the creation of BINARY (BINUS International Computer Society), and the BINUS International Computer Club as its Public Relations Head. 